\title{
ANALISIS SWOT PENGEMBANGAN USAHA PENGOLAHAN PASIR ZIRKON
}

\author{
SWOT Analysis of Business Development on Zircon Sand Processing
}

\author{
TRISWAN SUSENO \\ Puslitbang Teknologi Mineral dan Batubara \\ Jalan Jenderal Sudirman 623, Bandung 40211 \\ Telp. 022 6030483, Fax. 0226003373 \\ e-mail: triswan@tekmira.esdm.go.id
}

\begin{abstract}
ABSTRAK
Pemasaran pasir zirkon Indonesia untuk memenuhi kebutuhan industri di dalam negeri belum optimal hingga saat ini. Akibatnya, bahan mentah ini diekspor ke berbagai negara. Namun, sejak terbitnya UU Minerba Nomor 4 Tahun 2009 tentang larangan ekspor bahan mentah mineral, produksi pasir zirkon Indonesia cenderung mengalami penurunan yang berdampak pula pada menurunnya penerimaan negara bukan pajak bidang pertambangan yang bersumber dari royalti dan iuran tetap (dead rent), iuran produksi, iuran eksplorasi dan eksploitasi, pendapatan dari biaya reklamasi, pendapatan dari pajak penghasilan usaha dari pendapatan kena pajak dan pendapatan dari ekspor. Juga berakibat pemutusan hubungan kerja dan hilangnya sektor usaha lain di sekitar lokasi pertambangan yang selama ini menunjang kebutuhan bagi perusahaan pertambangan dan karyawannya. Menghadapi permasalahan tersebut, perlu dirumuskan strategi pengembangan yang tepat dan sesuai dengan posisi strategis keberadaan pertambangan pasir zirkon saat ini dan kondisi idealnya dengan mempertimbangkan faktor internal dan eksternal industri pengolahan. Hal ini untuk memetakan strategi kebijakan dan arah pengembangan yang akan dicapai serta langkah strategis mencapai kondisi tersebut. Dalam rangka mengidentifikasi posisi strategis pabrik zirkonium silikat lebih akurat dilakukan analisis strengths (kekuatan), weaknesses (kelemahan), opportunities (peluang) dan threats (ancaman). Indikator internal sistem digambarkan melalui kekuatan dan kelemahan, sedangkan indikator eksternal sistem digambarkan melalui peluang dan ancaman.
\end{abstract}

Kata kunci : pasir zirkon, zirkonium silikat, analisis strengths, weaknesses, opportunities, threats, harga.

\begin{abstract}
The marketing of Indonesia's zircon sand in fulfiling the domestic industry need is not optimal yet until now. The raw material of this commodity is mostly exported to several countries. Since the issue of the Law number 4 year 2009 concerning the ban of mineral raw materials, production of the zircon sand tends to decline. This decline affects a non-tax national revenue in the mining sector in terms of royalty, dead rent, production levy, exploration and exploitation levy, reclamation cost income, business income tax and export income. Moreover, this decline affects employment and loss of other business around mining sector that supports the mining company and its employees. To cope with those issues, a strategy of development is formulated towards the strategic position of the existing zircon mining and the ideal condition by considering external and internal factors of this industry. This is conducted in order to map the policy strategy and development direction using analysis of strengths, weaknesses, opportunities and threats. A internal indicator of system is illustrated through strengths and weaknesses, whilst an external indicator is through opportunities and threats.
\end{abstract}

Keywords: zircon sand, silicate zirconium, analysis of SWOT, price 


\section{PENDAHULUAN}

Terbitnya Peraturan Menteri Energi dan Sumber Daya Mineral Nomor 8 Tahun 2015 (Permen ESDM 8/2015) tentang Peningkatan Nilai Tambah Mineral Melalui Kegiatan Pengo-lahan dan Pemurnian Mineral di Dalam Negeri, khususnya pasir zirkon, cukup beralasan, karena berdasarkan hasil penelitian sebelumnya (Suseno dkk., 2015) menunjukkan bahwa pasir zirkon banyak dimanfaatkan oleh industri keramik, frit, bahan tahan api, dan pengecoran logam, setelah melalui pengolahan terlebih dahulu. Dua di antara beberapa produk hasil pengolahan pasir zirkon sebagaimana tercantum dalam Permen tersebut ternyata telah memberikan nilai tambah yang cukup signifikan dibandingkan dengan menjual pasir zirkon saja. Pasir zirkon yang harganya USD490 per ton, setelah diolah menjadi pasir zirkon $(\mathrm{ZrSiO}),\left(\mathrm{ZrO}_{2} \geq 65,5 \%\right)$ lolos saring 60 mesh $\geq 95 \%$, harganya menjadi USD900 per ton, atau 1,84 kali lebih tinggi dibandingkan harga pasir zirkon. Apabila diolah menjadi zirkonium silikat, harganya rata-rata sebesar USD1.800 per ton atau 3,67 kali lebih tinggi daripada harga pasir zirkon (Suseno, 2015b).

Berdasarkan hasil analisis pasar yang telah dilakukan Suseno dkk. (2015) terhadap keempat jenis industri pengguna akhir pasir zirkon, ternyata kebutuhan zirkonium silikat dalam negeri akan mengalami peningkatan yang cukup signifikan. Hal ini terlihat dari kebutuhan zirkonium silikat dari tahun 2014 sampai dengan tahun 2022, yang jumlahnya diperkirakan mencapai 1.235.171 ton. Jika melihat perilaku pengguna akhir, tampaknya zirkonium silikat sangat diperlukan oleh setiap kegiatan produksi keramik, frit, pengecoran logam, dan bata tahan api. Sedangkan pabrik pengolahan zirkonium silikat di Indonesia saat ini baru ada tiga perusahaan, dengan total produksi sekitar 37.500 ton per tahun (bandingkan dengan kebutuhan zirkonium silikat pada tahun 2014 yang jumlahnya 74.649 ton). Kondisi ini diperkirakan terus terjadi hingga tahun 2022, dengan jumlah kebutuhan mencapai 224.367 ton. Oleh karena itu, perusahaan yang ada harus meningkatkan kapasitas produksinya atau mengajak investor baru untuk mendirikan pabrik pengolahan zirkon untuk memenuhi kebutuhan industri di dalam negeri agar Indonesia tidak lagi menjadi pengimpor.
Peluang produk pengolahan zirkon Indonesia dalam menembus pasar industri keramik dunia pun cukup besar, mengingat ada beberapa negara penghasil keramik terbesar dunia sedikit atau bahkan tidak memiliki sumber daya pasir zirkon, seperti Brasil, Spanyol, Italia, Turki, Cina, India, Vietnam, Korea Selatan, Iran, Taiwan, Thailand, dan Malaysia (Suseno, 2015a). Tingginya kebutuhan pasir zirkon oleh industri keramik dunia membuat komoditas pasir zirkon banyak dicari, dan salah satunya adalah Indonesia. Sumber daya pasir zirkon di Indonesia cukup besar, yaitu di Kalimantan Barat sebanyak 167.141.100 ton, Kalimantan Tengah sekitar 2.615.509 ton dan Bangka Belitung sebesar 445.848 ton (Suseno dkk., 2015; Raja dkk., 2007; Sajima dkk., 2012).

Tujuan kajian ini adalah untuk memberikan gambaran analisis mengenai kekuatan (strengths), kelemahan (weaknesses), peluang (opportunities), dan ancaman (threats) (SWOT) pengembangan pabrik pengolahan pasir zirkon untuk kebutuhan industri manufaktur di dalam negeri. Analisis SWOT ini merupakan metode untuk mengidentifikasi dan menganalisis peran sebuah subyek (dalam hal ini pasir zirkon) dilihat dari segi kekuatan, kelemahan, peluang, dan ancaman untuk membangun rencana pengembangan pasir zirkon di masa yang akan datang untuk memenuhi kebutuhan industri dalam negeri. Arah kebijakan pengembangan diversifikasi produk ini penting, mengingat produk olahan pasir zirkon banyak diperlukan oleh dunia industri. Selain itu, tujuan dibuatnya tulisan ini adalah untuk memberikan gambaran atau informasi tentang peran perkembangan zirkon, seiring diberlakukannya Permen ESDM 8/2015.

\section{METODE}

\section{Pengumpulan Data}

Data yang digunakan dalam pengkajian ini terdiri atas data primer dan sekunder, baik yang bersifat kualitatif maupun kuantitatif. Data primer diperoleh melalui pengamatan dan pencatatan secara langsung di lapangan serta wawancara langsung dengan pihak perusahaan. Data sekunder diperoleh dari studi pustaka berbagai instansi berupa hasilhasil penelitian terdahulu, pabrik pengolahan pasir zirkon PT. Dian Lestari Sejahtera, serta 
literatur lainnya yang bersangkutan dengan penelitian ini. Data yang diperoleh diolah dan dianalisis melalui dua cara, yaitu secara kuantitatif dan kualitatif. Analisis data kuantitatif diolah dan disajikan dalam bentuk tabel dan gambar setelah melalui proses tabulasi data. Sedangkan analisis kualitatif adalah proses analisis kualitatif yang mendasarkan pada adanya hubungan semantis antarvariabel yang sedang diteliti (Sutopo dan Arief, 2010).

\section{Analisis SWOT}

Analisis SWOT zirkon adalah salah satu metode untuk membangun strategis peran pasir zirkon dalam industri dengan menggunakan kerangka kerja kekuatan dan kelemahan serta kesempatan ekternal dan ancaman (Maharani dkk., 2010). Instrumen ini digunakan untuk membantu rencana pengembangan pasir zirkon di masa yang akan datang di dalam dunia industri. Tujuannya adalah untuk memberikan gambaran hasil analisis keunggulan, kelemahan, peluang, dan ancaman pengolahan pasir zirkon untuk kebutuhan industri manufaktur di dalam negeri (Susanto dkk., 2012).

Faktor-faktor internal yang dapat dianalisis yaitu:

- Kekuatan dan
- Kelemahan

Sedangkan faktor-faktor eksternal, yaitu:

- Peluang dan

- Ancaman

Setelah hasil analisis SWOT dilakukan dengan menghasilkan faktor-faktor internal (kekuatan dan kelemahan) dan eksternal (peluang dan ancaman) (Nurbasari, 2012), maka berdasarkan hasil tersebut digunakan untuk menentukan strategi-strategi, yaitu:

1. Strategi SO dengan mengembangkan suatu strategi dalam memanfaatkan kekuatan (S) untuk mengambil manfaat dari peluang $(\mathrm{O})$ yang ada.

2. Strategi WO yaitu mengembangkan suatu strategi dalam memanfaatkan peluang $(\mathrm{O})$ untuk mengatasi kelemahan (W) yang ada.

3. Strategi ST yaitu dengan mengembangkan suatu strategi dalam memanfaatkan kekuatan (S) untuk menghindari ancaman (T).

4. Strategi WT yaitu dengan mengembangkan suatu strategi dalam mengurangi kelemahan (W) dan menghindari ancaman (T).

Berdasarkan hasil analisis faktor-faktor SWOT di atas ditetapkan strategi (Antara dan Sugesty, 2011) seperti di bawah ini:

\begin{tabular}{|c|c|c|}
\hline \multirow{2}{*}{ Faktor internal } & \multicolumn{2}{|c|}{ Faktor eksternal } \\
\hline & Kekuatan/Strengths (S) & Kelemahan/Weaknesses (W) \\
\hline Peluang/opportunities $(\mathrm{O})$ & 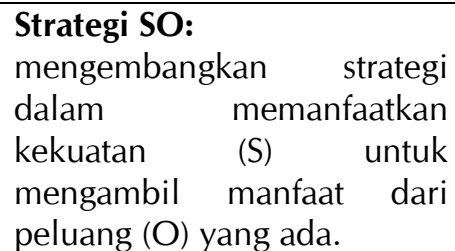 & $\begin{array}{l}\text { Strategi WO: } \\
\text { mengembangkan strategi } \\
\text { dalam memanfaatkan peluang } \\
(\mathrm{O}) \quad \text { untuk mengatasi } \\
\text { kelemahan }(\mathrm{W}) \text { yang ada. }\end{array}$ \\
\hline Ancaman/Threats (T) & $\begin{array}{l}\text { Strategi ST: } \\
\text { mengembangkan strategi } \\
\text { dalam } \quad \text { memanfaatkan } \\
\text { kekuatan (S) untuk } \\
\text { menghindari ancaman }(\mathrm{T}) \text {. }\end{array}$ & $\begin{array}{l}\text { Strategi SO: } \\
\text { mengembangkan strategi } \\
\text { dalam mengurangi kelemahan } \\
(\mathrm{W}) \quad \text { dan menghindari } \\
\text { ancaman }(\mathrm{T}) \text {. }\end{array}$ \\
\hline
\end{tabular}




\section{HASIL DAN PEMBAHASAN}

\section{Sumber Daya, Produksi, dan Umur Tambang}

Berdasarkan perhitungan Suseno dkk. (2015), hingga tahun 2022, kebutuhan zirkonium silikat Indonesia diperkirakan akan naik sebesar 122.535 ton per tahun, yang berarti dibutuhkan bahan baku pasir zirkon sebesar 408.450 ton. Apabila jumlah sumber daya pasir zirkon Indonesia sekitar 167.141.100 ton, maka umur tambang diperkirakan mencapai lebih dari 100 tahun. Jumlah sumber daya tersebut masih berupa data hipotetik, sehingga harus dilakukan penelitian lanjut, karena pasir zirkon sebagai mineral ikutan juga dapat dijumpai pada endapan emas dan timah aluvial (Suprapto, 2012).

\section{Kajian Pembangunan Pabrik Pasir Zirkon ( $\left.\mathrm{ZrSiO}_{4}\right),\left(\mathrm{ZrO}_{2} \geq 65,5 \%\right)$ dan Zirkonium Silikat}

- Kecenderungan global pengusahaan pasir zirkon

Hingga saat ini, pemasaran pasir/konsentrat zirkon Indonesia untuk memenuhi kebutuhan industri di dalam negeri belum optimal, akibatnya bahan mentah ini banyak diekspor ke berbagai negara, terutama ke Cina $(96,26 \%)$ sisanya ke Jepang, Korea Selatan, Thailand dan Taiwan (Kemendag, 2013).

- Kecenderungan yang telah terjadi
Sejak terbitnya UU 4/2009 tentang Pertambangan Mineral dan Batubara, yang salah satu di antaranya memuat kewajiban pengolahan dan/atau pemurnian mineral di dalam negeri sebelum diekspor, produksi pasir zirkon Indonesia cenderung mengalami penurunan (Gambar 1). Produksi pasir zirkon tahun 2007-2010 turun sebesar $36,67 \%$. Walaupun tahun 2011 sempat naik cukup signifikan, namun tahun 2012 produksinya menurun kembali hingga $85,58 \%$. Hal ini menunjukkan bahwa terbitnya peraturan tersebut sangat efektif dalam mengendalikan produksi pasir zirkon dalam negeri.

- Kecenderungan yang akan terjadi

- Menurunnya kegiatan produksi pertambangan pasir zirkon untuk sementara akan mengurangi pendapatan pusat/daerah, antara lain: penerimaan negara bukan pajak bidang pertambangan yang bersumber dari royalti dan iuran tetap (dead rent), iuran produksi (2,5\% dari harga jual per ton), iuran eksplorasi dan eksploitasi, pendapatan dari biaya reklamasi, pendapatan dari pajak penghasilan usaha $(12,5 \%$ dari pendapatan kena pajak), dan pendapatan dari ekspor.

- Terjadinya pemutusan hubungan kerja dan hilangnya sektor usaha lain di sekitar lokasi pertambangan yang selama ini menunjang kebutuhan bagi perusahaan pertambangan dan karyawannya.

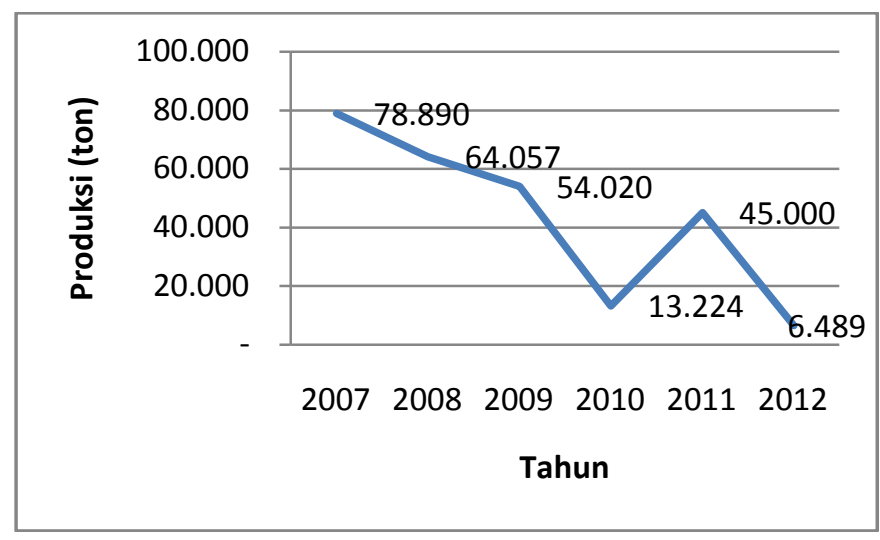

Sumber :

Kaltengmining.com, Distamben Bangka-Belitung, Kalimantan Tengah dan Kalimantan Barat (2013), diolah kembali.

Gambar 1. Perkembangan produksi pasir zirkon Indonesia, tahun 2007-2012 (ton) 


\section{Industri hulu}

Kegiatan usaha pengolahan pasir zirkon (hulu) siap digunakan untuk memenuhi kebutuhan domestik dan ekspor.

\section{Industri pendukung}

Bahan bakar minyak (solar), batubara, listrik dan bola alumina menjadi bagian yang mendukung keberlangsungan pengolahan pasir zirkon.

\section{Industri hilir}

Akan lebih banyak lagi industri yang akan memanfaatkan pasir zirkon hasil pengolahan, terutama di sektor konstruksi dan bangunan, seperti industri keramik, frit, refraktori, pasir cetak, kimia dan lain-lain.

Beberapa permasalahan yang dihadapi oleh industri pengolahan pasir zirkon adalah:

- Isu lingkungan, sehingga pasir zirkon $\left(\mathrm{ZrSiO}_{4}\right),\left(\mathrm{ZrO}_{2} \geq 65,5 \%\right)$ dan zirkonium silikat sulit diterima oleh industri hilir (khususnya industri keramik) di dalam negeri, karena mengandung unsur radioaktif berupa uranium dan thorium.

- Masih adanya gangguan pasir zirkon $(\mathrm{ZrSiO}),\left(\mathrm{ZrO}_{2} \geq 65,5 \%\right)$ dan zirkonium silikat impor; selain harga lebih murah, juga karena tidak dikenakan pajak impor, sehingga produk Indonesia sulit bersaing.

- Masih tingginya impor pasir zirkon ( $\mathrm{ZrSiO} 4)$, $\left(\mathrm{ZrO}_{2} \geq 65,5 \%\right)$, dan zirkonium silikat, karena belum banyak pabrik pengolahan zirkon silikat di dalam negeri.

- Kekhawatiran masih diberlakukannya aturan pajak ekspor $20 \%$ bagi produk zirkonium silikat, sehingga sulit bersaing di pasar dunia.

\section{Analisis terhadap Kondisi Saat Ini dan Kemungkinan di Masa Mendatang}

Prospek pengolahan pasir zirkon $\left(\mathrm{ZrSiO}_{4}\right)$, $\left(\mathrm{ZrO}_{2} \geq 65,5 \%\right)$, dan zirkonium silikat dalam beberapa tahun ke depan diperkirakan cukup cerah. Hal ini mengingat komoditas zirkon banyak digunakan untuk proses pembuatan keramik, karena permintaan keramik dalam negeri cukup tinggi, seiring banyaknya pembangunan perumahan, hotel, apartemen, dan gedung perkantoran lainnya berkembang sangat pesat. Keunggulan yang dimiliki oleh produk zirkonium silikat Indonesia, selain tingkat pewarnaan yang sangat baik diban- dingkan dengan produk negara lain, juga karena memiliki sumber daya cukup besar, sehingga mampu meningkatkan daya saing dengan produk yang sama dari negara lain.

Untuk menghadapi persaingan pasar global yang semakin ketat, industri keramik perlu melakukan peningkatan daya saing melalui inovasi dan teknologi untuk menghasilkan produk zirkon yang kualitas tinggi untuk kebutuhan industri yang berteknologi tinggi. Produk yang dimaksud adalah zirkonia, produk ini sebagai oksida yang berfungsi pada berbagai aplikasi keramik maju (advanced ceramics), seperti sensor oksigen dan SOFC (Solid oxide Fuel Cell). Kegunaan zirkonia lainnya adalah untuk aplikasi kesehatan (terutama sebagai heads untuk hydroxyapatite), elektronik, optik, katalis, perhiasan dan sebagainya, sehingga penguasaan teknologi pembuatannya sangat diperlukan (Dahlan dkk, 2014 dan www.litbang.esdm.go.id, 2015). Pemakaian zirkonia dengan kualitas tinggi sampai saat ini masih bergantung kepada produk impor.

1) Pangsa pasar

Kebutuhan dan pemasokan zirkonium silikat

Peluang pasar pasir zirkon $\left(\mathrm{ZrSiO}_{4}\right),\left(\mathrm{ZrO}_{2}\right.$ $\geq 65,5 \%$ ) dan zirkonium silikat Indonesia, baik di dalam maupun luar negeri, akan dipengaruhi oleh produk dari negara lain:

- Kebutuhan pasir zirkon $\left(\mathrm{ZrSiO}_{4}\right),\left(\mathrm{ZrO}_{2}\right.$ $\geq 65,5 \%$ ) dan zirkonium silikat akan terus meningkat, terutama di negara Cina, sebagai salah satu penghasil keramik terbesar dunia yang akan membutuhkan lebih banyak produk ini, disusul kemudian oleh Amerika Serikat, Korea Selatan, Jepang, dan Malaysia (Poernomo, 2012).

- Pesaing pemasok pasir zirkon $\left(\mathrm{ZrSiO}_{4}\right)$, $\left(\mathrm{ZrO}_{2} \geq 65,5 \%\right)$ dan zirkonium silikat Indonesia adalah Australia, Afrika Selatan dan Cina, karena ketiga negara memiliki sumber daya pasir zirkon terbesar dunia (Poernomo, 2012).

- Kebutuhan zirkonium silikat di dalam negeri antara tahun 2014-2022 akan naik 122.535 ton per tahun.

Perilaku pasar

Industri keramik adalah industri hilir yang paling banyak menggunakan zirkon, indus- 
tri ini menggunakan sekitar $55 \%$ produksi zirkon dunia, disusul industri bahan kimia (18\%), bahan-bahan tahan api $(14 \%)$, pasir cetak dalam industri pengecoran logam $(10 \%)$ dan industri lainnya $3 \%$ (www.mineraldeposits.com.au, 2013).

2) Faktor kondisi (input)

Sumber daya

Pasir zirkon tersebar di Provinsi BangkaBelitung, Kalimantan Tengah, dan Kalimantan Barat.

Sumber daya modal

- Untuk membangun pabrik zirkonium silikat dengan kapasitas 7.000 ton per tahun diperlukan investasi sebesar Rp.74.450.000.000. Sedangkan pengolahan pasir zirkon $\left(\mathrm{ZrSiO}_{4}\right)$ dengan kadar minimum $\mathrm{ZrO}_{2} \geq 65,5 \%$, diperlukan modal sebesar Rp. 41.926.400.000 (Suseno, 2015b).

- Pembiayaan untuk industri dan suku bunga bank masih tinggi dibandingkan dengan negara lain, Indonesia (14$15 \%$ fluktuatif), Cina, Vietnam, dan Thailand (>6\%, 6\% dan $4 \%$ stabil)

- Daya tarik investasi Indonesia masih rendah dibanding negara lain. PPh badan Indonesia 25\% (UU 36/2008 tentang PPh), Hongkong 20\%, Malaysia $10 \%$, Cina dan Thailand 20\%, serta Vietnam $15 \%$.

3) Sumber daya manusia

- Tersedia tenaga kerja yang terampil dan mampu menguasai teknologi pengolahan pasir zirkon $\left(\mathrm{ZrSiO}_{4}\right),\left(\mathrm{ZrO}_{2}\right.$ $\geq 65,5 \%$ ) dan zirkonium silikat dan pengolahan produk zirkon lainnya.

- Dukungan penelitian dan pengembangan dalam pembinaan sumber daya manusia dan penerapan standar nasional Indonesia (SNI).

- Belum menguasai rancang bangun dan perekayasaan untuk teknologi pengolahan zirkonia dan produk zirkon lainnya yang berbasis pasir zirkon.

4) Infrastruktur

- Sarana dan prasarana transportasi belum mendukung baik di lokasi penambangan ke lokasi pabrik pengolahan pasir zirkon $\left(\mathrm{ZrSiO}_{4}\right),\left(\mathrm{ZrO}_{2} \geq 65,5 \%\right)$ dan zirkonium silikat atau ke produk zirkon lainnya.
- Industri manufaktur pengguna pasir zirkon $\left(\mathrm{ZrSiO}_{4}\right),\left(\mathrm{ZrO}_{2} \geq 65,5 \%\right)$ dan zirkonium silikat masih terkonsentrasi di Pulau Jawa.

5) Industri inti, penunjang dan terkait

- Industri inti: industri pengolahan pasir zirkon $\left(\mathrm{ZrSiO}_{4}\right), \quad\left(\mathrm{ZrO}_{2} \geq 65,5 \%\right)$, zirkonium silikat dan produk zirkon lainnya.

- Industri penunjang: industri pertambangan pasir zirkon, perusahaan batubara, PLN, Pertamina, bola alumina.

- Industri/lembaga terkait: industri permesinan, Puslitbang tekMIRA.

- Industri pengguna: industri keramik, kimia, pengecoran logam, nuklir, dan lain-lain.

6) Strategi pengusaha dan perusahaan

- Kerja sama bidang pengembangan pasir zirkon antara negara penghasil pasir zirkon dan dengan negara yang menguasai teknologi.

- Mengadakan kerja sama antara pengolah pasir zirkon $\left(\mathrm{ZrSiO}_{4}\right),\left(\mathrm{ZrO}_{2}\right.$ $\geq 65,5 \%$ ) dan zirkonium silikat dengan pemakainya di Indonesia, melalui berbagai forum.

- Menerapkan bea masuk terhadap pasir zirkon dan zirkonium silikat dari luar negeri yang tinggi, misalnya sebesar $30 \%$.

\section{ANALISIS SWOT}

Dalam rangka penyusunan kajian akademis pabrik pengolahan pasir zirkon $\left(\mathrm{ZrSiO}_{4}\right),\left(\mathrm{ZrO}_{2}\right.$ $\geq 65,5 \%$ ) dan zirkonium silikat perlu dirumuskan strategi pengembangan yang tepat dan sesuai dengan posisi strategis keberadaan pertambangan pasir zirkon saat ini dan kondisi idealnya dengan mempertimbangkan faktor internal dan eksternal industri pengolahan tersebut. Hal ini untuk memetakan dengan baik strategi kebijakan dan arah pengembangan yang akan dicapai serta langkah strategis untuk mencapai kondisi tersebut.

Dalam rangka mengidentifikasi posisi strategis pabrik zirkonium silikat dengan lebih akurat, maka perlu dilakukan analisis SWOT. Indikator internal sistem digambarkan melalui kekuatan dan kelemahan, sedangkan indi- 
kator eksternal sistem digambarkan melalui peluang dan ancaman.

\section{Kekuatan}

- Tersedianya sumber daya pasir zirkon.

- Kemampuan mengolah pasir zirkon $(\mathrm{ZrSiO}),\left(\mathrm{ZrO}_{2} \geq 65,5 \%\right)$ dan zirkonium silikat dan produk hilirisasi zirkon lainnya.

- Penguasaan teknologi zikonia untuk teknologi tinggi.

- Dukungan lembaga penelitian dan pengembangan (litbang) Puslitbang tekMIRA dan lembaga litbang lainnya.

- Dukungan asosiasi pertambangan dan pemerintah.

\section{Kelemahan}

- Belum ada fasilitasi penyiapan pasir/ konsentrat zirkon.

- Jumlah pabrik pasir zirkon $\left(\mathrm{ZrSiO}_{4}\right),\left(\mathrm{ZrO}_{2}\right.$ $\geq 65,5 \%$ ) dan zirkonium silikat masih sedikit.

- Zirkonium silikat dan pasir zirkon $\left.(\mathrm{ZrSiO})_{4}\right),\left(\mathrm{ZrO}_{2} \geq 65,5 \%\right)$ sebagian besar masih diimpor.

- Jalur distribusi belum efisien (banyak mengeluarkan biaya pengangkutan atau ekonomi biaya tinggi)

- Sebagian besar bahkan $100 \%$ mesin produksi pengolahan zirkonium silikat masih impor.

- Belum diberlakukannya SNI wajib produk pasir zirkon $\left(\mathrm{ZrSiO}_{4}\right),\left(\mathrm{ZrO}_{2} \geq 65,5 \%\right)$ dan zirkonium silikat dari dalam dan luar negeri, terkait unsur radioaktif dalam uranium dan thorium.

\section{Peluang}

- Potensi pasar dalam negeri tetap terbuka, karena tingginya kebutuhan zirkon silikat oleh industri manufaktur, yakni sekitar 122.535 ton per tahun.

- Adanya potensi pasar luar negeri terbesar, yaitu Cina, karena tingginya pertumbuhan di sektor konstruksi dan bangunan. Selain itu, ada Italia, Spanyol, Vietnam dan Turki.

\section{Ancaman}

- Kebijakan pengenaan tarif masuk (impor) pasir zirkon $\left(\mathrm{ZrSiO}_{4}\right),\left(\mathrm{ZrO}_{2} \geq 65,5 \%\right)$ dan zirkonium silikat sebesar $0 \%$.
- Tuntutan negara tujuan ekspor dan pemakai dalam negeri yang makin tinggi terutama dengan dengan masalah mutu dan lingkungan.

\section{Sasaran}

\section{Jangka pendek:}

- mengkaji ulang sumber daya pasir zirkon di Indonesia;

- pengamanan pasokan bahan baku dalam negeri;

- pengembangan pemanfaatan bahan baku pasir zirkon di Kalimantan Barat, Kalimantan Tengah, dan Bangka-Belitung;

- meningkatkan daya saing industri pengolahan pasir zirkon $\left(\mathrm{ZrSiO}_{4}\right), \quad\left(\mathrm{ZrO}_{2} \geq\right.$ $65,5 \%$ ) dan zirkonium silikat di dalam negeri dan pasar dunia;

- menerapkan kebijakan impor pasir zirkon ( $\mathrm{ZrSiO} 4),\left(\mathrm{ZrO}_{2} \geq 65,5 \%\right)$, dan zirkonium silikat dengan kebijakan pajak yang tinggi dan/atau menerapkan SNI terkait dengan produk yang dihasilkan;

- memperkuat struktur hilirisasi industri pengolahan pasir zirkon mulai dari bahan baku hingga produk yang akan digunakan oleh industri manufaktur;

- meningkatkan peran produk pasir zirkon $\left(\mathrm{ZrSiO}_{4}\right),\left(\mathrm{ZrO}_{2} \geq 65,5 \%\right)$, dan zirkonium silikat di dalam negeri untuk kebutuhan domestik;

- memberikan kewenangan kepada suatu lembaga yang mengawasi kandungan radiasi dalam setiap produk berbahan pasir zirkon Indonesia dan membrikan sertifikasi layak jual dalam rangka melindungi produk dalam negeri;

- mempromosikan investasi industri pengolahan pasir zirkon $\left(\mathrm{ZrSiO}_{4}\right), \quad\left(\mathrm{ZrO}_{2}\right.$ $\geq 65,5 \%$ ), dan zirkonium silikat.

\section{Jangka menengah:}

- mengembangkan pencarian sumber daya pasir zirkon ke daerah lainnya di Indonesia;

- mengembangkan hilirisasi industri pasir zirkon yang bernilai tambah tinggi (seperti zirkonia, dan zirconium oxychloride atau zirconil chloride) untuk memenuhi kebutuhan domestik dan ekspor;

- memenuhi pasokan energi untuk kebutuhan industri pengolahan pasir zirkon; 
- melakukan koordinasi dengan pemerintah daerah dan pengusaha pengolahan pasir zirkon $\left(\mathrm{ZrSiO}_{4}\right),\left(\mathrm{ZrO}_{2} \geq 65,5 \%\right)$ dan zirkonium silikat dalam rangka pengembangan industri inti di daerah, khususnya penggunaan bahan-bahan baku yang tersedia di dalam negeri;

- mengembangkan rekayasa dan fabrikasi pabrik pengolahan produk pasir zirkon lainnya yang hemat energi.

\section{Jangka panjang:}

- menerapkan dan pengawasan terhadap $\mathrm{SNI} ;$

- mengembangkan diversifikasi hilirisasi industri pengolahan pasir zirkon bernilai tambah tinggi (advanced zircon) sebagaimana yang tercantum dalam Permen ESDM 8/2015;

- mengembangkan kompetensi sumber daya manusia bagi diversifikasi hilirisasi industri pengolahan pasir zirkon (lihat Tabel 1) sesuai dalam lampiran Permen ESDM 8/2015;

- mengembangkan rancang bangun dan fabrikasi pabrik pengolahan pasir zirkon yang hemat energi.

Kerangka pengembangan industri pengolahan pasir zirkon $\left(\mathrm{ZrSiO}_{4}\right),\left(\mathrm{ZrO}_{2} \geq 65,5 \%\right)$, zirkonium silikat, dan diversifikasi pengolahan produk-produk pasir zirkon lainnya harus ditunjang oleh infrastruktur ekonomi yang memadai seperti teknologi, sumber daya manusia, pasar, sarana dan prasarana transportasi untuk menghasilkan nilai tambah yang lebih tinggi (Djamaluddin dkk., 2012).

Berdasarkan hasil penelitian dan kajian mengenai keberadaan zirkon dari aspek pengusahaannya, ternyata dapat diambil beberapa manfaat dari hasil pengolahan pasir zirkon menjadi pasir zirkon $\left(\mathrm{ZrSiO}_{4}\right),\left(\mathrm{ZrO}_{2}\right.$ $\geq 65,5 \%$ ) lolos saring 60 mesh $\geq 95 \%$ dan zirkonium silikat terhadap industri hulu dan hilir baik langsung maupun tidak langsung.

\section{Keterkaitan industri hulu:}

1. Sektor pertambangan pasir dan konsentrat zirkon.

2. Untuk kegiatan produksinya, pabrik pengolahan pasir zirkon $\left(\mathrm{ZrSiO}_{4}\right),\left(\mathrm{ZrO}_{2}\right.$ $\geq 65,5 \%$ ), dan zirkonium silikat sangat membutuhkan energi seperti listrik, batubara dan solar.
3. Bahan baku besi untuk pembangunan konstruksi dan membuat mesin/konstruksi pendirian pabrik pengolahan pasir zirkon.

4. Bola-bola penggerus yang terbuat dari bahan alumina.

5. Tenaga kerja sebagai tenaga operasional dan administrasi dalam menunjang kelancaran kegiatan perusahaan.

\section{Keterkaitan industri hilir:}

1. Industri keramik.

2. Industri refraktori.

3. Pasir cetak pada industri pengecoran logam.

4. Frit.

5. Industri ruang angkasa dan pesawat terbang, industri baja zirkonium atau industri pembangkit listrik tenaga nuklir.

Keterkaitan tak langsung dari kegiatan usaha ini adalah akan menghasilkan devisa negara dari ekspor pasir zirkon $\left(\mathrm{ZrSiO}_{4}\right), \quad\left(\mathrm{ZrO}_{2}\right.$ $\geq 65,5 \%$ ) dan zirkonium silikat, menciptakan perdagangan produk zirkon yang lebih beragam, kegiatan perbankan melalui pinjaman modal untuk investasi di pengolahan zirkonium silikat dan produk zirkon lainnya. Sedangkan manfaat hilir akan diperoleh adalah pendapatan negara dari pajak penghasilan badan usaha pengolahan zirkonium silikat dan produk zirkon lainnya.

Harga pasir zirkon saat ini sekitar USD490 per ton, namun setelah diolah menjadi pasir zirkon $\left(\mathrm{ZrSiO}_{4}\right),\left(\mathrm{ZrO}_{2} \geq 65,5 \%\right)$ lolos saring 60 mesh $\geq 95 \%$ harganya menjadi USD900 per ton, atau 1,84 kali lebih tinggi dibandingkan harga pasir zirkon. Sedangkan zirkonium silikat harganya rata-rata sebesar USD1.800 atau 3,67 kali lebih tinggi. Produk lain hasil dari pengolahan dan pemurnian pasir zirkon menjadi produk yang bernilai tinggi sebagaimana diamanatkan dalam Permen ESDM 1/2014 dapat dilihat dalam Tabel 1.

Permen ESDM tersebut dapat direalisasikan oleh para pemegang Izin Usaha Pertambangan apabila seluruh pemangku kepentingan terkait, seperti lembaga litbang, lembaga keuangan dan perbankan, investor, dan perguruan tinggi terlibat di dalamnya. Oleh karena itu, harus ada rencana strategis jangka panjang agar Permen ini dapat terwujud dan dirasakan manfaatnya oleh semua pihak. 
Tabel 1 Jenis produk, manfaat dan harga hasil pengolahan dan/pemurnian pasir zirkon untuk memenuhi kebutuhan berbagai industri pengguna akhir

\begin{tabular}{|c|c|c|}
\hline $\begin{array}{l}\text { Jenis produk dan formula dari } \\
\text { pengolahan pasir zirkon }\end{array}$ & Manfaat/aplikasi & $\begin{array}{l}\text { Harga } \\
\text { (US\$/ton) }\end{array}$ \\
\hline Zirkonia $\left(\mathrm{ZrO}_{2}+\mathrm{HfO}_{2}\right) \geq 99 \%$ & $\begin{array}{l}\text { Untuk komponen mesin jet, reaktor } \\
\text { nuklir }\end{array}$ & $\begin{array}{l}\text { 10.000 - } 14.600 \\
\text { (tergantung spesifikasi, lihat } \\
\text { Poernomo (2012) hal. 7, 50 }\end{array}$ \\
\hline $\begin{array}{l}\text { Pasir zirkon }(\mathrm{ZrSiO}),\left(\mathrm{ZrO}_{2} \geq\right. \\
65,5 \%) \text { lolos saring } 60 \text { mesh } \\
\geq 95 \% \\
\text { Zirkonium silikat }(\mathrm{ZrSiO}) \\
(\mathrm{ZrO}) \geq 64 \%) \text { lolos saring } \\
325 \text { mesh } \geq 95 \%\end{array}$ & $\begin{array}{l}\text { untuk opacifier keramik setelah mellui } \\
\text { proses pengolahan menjadi zirkonium } \\
\text { silikat }\end{array}$ & (6) \\
\hline $\begin{array}{l}\text { Zirkonium silikat }\left(\mathrm{ZrSiO}_{4}\right) \\
\left(\mathrm{ZrO}_{2} \geq 63 \%\right) \text { lolos saring } \mathrm{d}_{50} \\
=1,43 \pm 0,16 \mu \mathrm{m}\end{array}$ & $\begin{array}{l}\text { Digunakan dalam industri keramik, kaca, } \\
\text { bahan tahan api, frit dan pengecoran } \\
\text { logam }\end{array}$ & $\begin{array}{l}\text { 1.400-1.900 } \\
\text { (http://www.alibaba.com, 2014) }\end{array}$ \\
\hline & $\begin{array}{l}\text { digunakan dalam industri tekstil, industri } \\
\text { karet, cat/pengeringan, bahan tahan api, } \\
\text { keramik } \\
\text { digunakan pula untuk pembuatan garam }\end{array}$ & \\
\hline 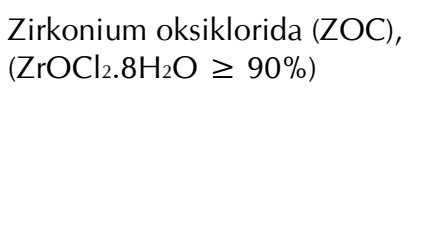 & $\begin{array}{l}\text { lainnya zirkonium, pencelupan tekstil, } \\
\text { ladang minyak pengasaman, dalam } \\
\text { kosmetik dan gemuk, dan antiperspirant } \\
\text { dan penolak air dan lapisan } \mathrm{TiO}_{2} \\
\text { pigmen. } \\
\text { (http://www.chemicalland21.com) }\end{array}$ & $\begin{array}{l}\text { 1.000-3.000 } \\
\text { (http://www.alibaba.com, 2014) }\end{array}$ \\
\hline Zirkonium sulfat (ZOS), & $\overline{\text { digunakan sebagai reagen analitis, }}$ & $2.600-3.500$ \\
\hline $\mathrm{Zr}\left(\mathrm{SO}_{4}\right)_{2} \cdot \mathrm{xH}_{2} \mathrm{O} \geq 90 \%$ & $\begin{array}{l}\text { koagulan, dan operator radioaktif fosfor. } \\
\text { (http://www.chemicalland21.com) } \\
\text { digunakan dalam aplikasi seperti }\end{array}$ & (http://www.alibaba.com/) \\
\hline $\begin{array}{l}\text { Zirkonium berbasis sulfat } \\
(\mathrm{ZBS}), \mathrm{Zr}_{5} \mathrm{O}_{8}\left(\mathrm{SO}_{4}\right)_{2 .} 4 \mathrm{H}_{2} \mathrm{O} \geq \\
90 \%\end{array}$ & $\begin{array}{l}\text { penyamakan kulit dan pigmen titanium } \\
\text { dioksida, tetapi juga sering dikonversi } \\
\text { menjadi bahan kimia zirkonium lain dan } \\
\text { oksida } \\
\text { (http://www.abscomaterials.com, } 2014 \text { ) } \\
\text { digunakan dalam pembuatan garam }\end{array}$ & $\begin{array}{l}12.580 \\
\text { (Poernomo (2012) }\end{array}$ \\
\hline $\begin{array}{l}\text { Zirkonium berbasis karbonat } \\
\text { (ZBC) } \mathrm{ZrOCO}_{3} . \mathrm{xH}_{2} \mathrm{O} \geq 90 \%\end{array}$ & $\begin{array}{l}\text { zirkonium, cat kering, pembuatan kertas, } \\
\text { pelembut kulit, kosmetik, katalis, } \\
\text { keramik, pengering lacquer dan lain-lain }\end{array}$ & $\begin{array}{l}2.000-3.000 \\
\text { (http://cjmetal.en.made-in- } \\
\underline{\text { china.com) }}\end{array}$ \\
\hline $\begin{array}{l}\text { Amonium zirkonium karbonat } \\
\text { (AZC), } \\
\left(\mathrm{NH}_{4}\right)_{3} \mathrm{ZrOH}\left(\mathrm{CO}_{3}\right)_{3} .2 \mathrm{H}_{2} \mathrm{O} \geq \\
90 \%\end{array}$ & $\begin{array}{l}\text { digunakan dalam pelapisan kertas, cat } \\
\text { dan formulasi tinta, pengobatan } \\
\text { permukaan logam, perekat, katalis } \\
\text { (http://dir.indiamart.com/impcat/zirkoniu } \\
\text { m-carbonate.html) }\end{array}$ & $\begin{array}{l}\text { 2.000-2.700 } \\
\text { (http://www.alibaba.com, 2914) }\end{array}$ \\
\hline $\begin{array}{l}\text { Zirkonium asetat (ZAC) } \\
\mathrm{H}_{2} \mathrm{ZrO}_{2}\left(\mathrm{C}_{2} \mathrm{H}_{3} \mathrm{O}_{2}\right)_{2} \geq 90 \%\end{array}$ & $\begin{array}{l}\text { digunakan sebagai emulsi Zirkonium- } \\
\text { lilin, Refractory Binder dan Katalis } \\
\text { (http://www.dixonchew.com) }\end{array}$ & $\begin{array}{l}\text { 10.000-30.000 } \\
\text { (http://www.alibaba.com, 2014) }\end{array}$ \\
\hline $\begin{array}{l}\text { Kalium heksafloro zirkonat } \\
\text { (KFZ) } \mathrm{K}_{2} \mathrm{ZrF}_{6} \geq 90 \% \\
\text { (atau Potassium } \\
\text { hexafluorozirkonate) } \\
\text { (http://www.sigmaaldrich.com) }\end{array}$ & $\begin{array}{l}\text { digunakan dalam pengolahan logam, } \\
\text { sebagai katalis dalam pembuatan kimia, } \\
\text { dan untuk keperluan lainnya }\end{array}$ & $4.700-7.000$ \\
\hline Zirkonium spon & $\begin{array}{l}\text { digunakan dalam produksi logam } \\
\text { zirkonium dan paduan, terutama untuk } \\
\text { digunakan dalam bahan bakar nuklir } \\
\text { cladding, korosi pipa tahan dalam proses }\end{array}$ & $\begin{array}{l}32.185 \\
\text { (http://www.metalprices.com, }\end{array}$ \\
\hline
\end{tabular}




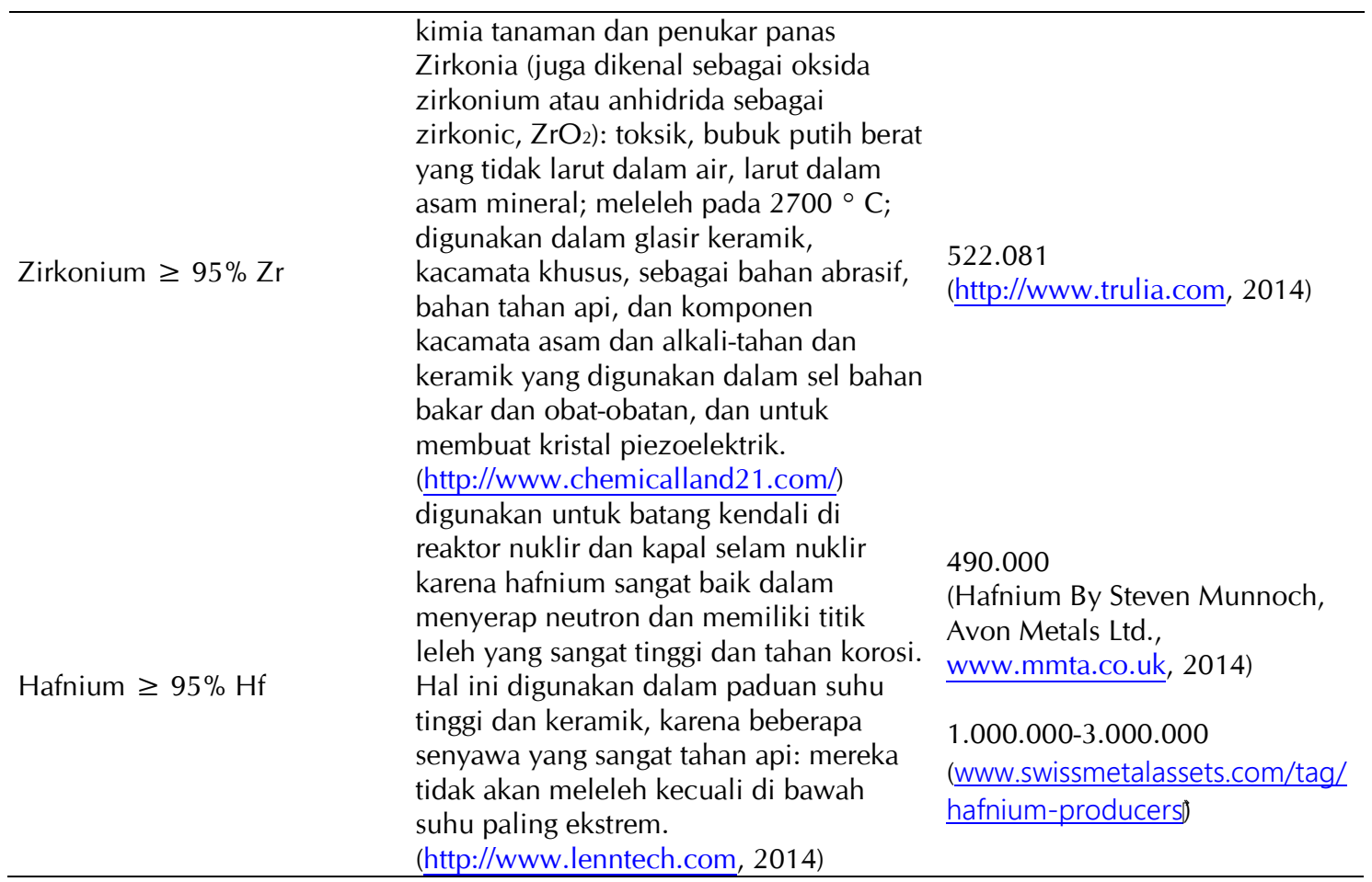

\section{KESIMPULAN DAN SARAN}

\section{Kesimpulan}

Berdasarkan hasil analisis SWOT dapat disimpulkan bahwa:

- Dari sisi kekuatan, Indonesia memiliki sumber daya pasir zirkon yang cukup besar dan memiliki kemampuan dan penguasaan teknologi untuk meningkatkan kualitas pasir zirkon.

- Kelemahannya adalah kegiatan pengusahaan pasir zirkon belum didukung infrastruktur transportasi dan distribusi yang memadai untuk mengurangi biaya ekonomi tinggi.

- Pengusahaan pasir zirkon memiliki peluang pasar yang cukup besar, baik di dalam maupun di luar negeri.

- Kebijakan pengenaan tarif masuk (pajak impor) pasir zirkon $\left(\mathrm{ZrSiO}_{4}\right), \quad\left(\mathrm{ZrO}_{2}\right.$ $\geq 65,5 \%$ ) dan zirkonium silikat sebesar $0 \%$, dikhawatirkan akan mengancam pengusaha zirkon di dalam negeri.

\section{Saran}

- Untuk mengantisipasi tingginya arus ekspor produk pengolahan zirkon yang diizinkan berdasarkan Permen ESDM 8/2015, maka sejak dini harus disiapkan kebijakan tentang pengamanan pasokan bahan baku dalam negeri.

- Cara lain untuk menghambat tinggi arus ekspor, sebaiknya diterapkan kebijakan pajak yang tinggi terhadap produk ekspor tersebut.

- Meningkatkan peran produk pasir zirkon ( $\mathrm{ZrSiO} 4),\left(\mathrm{ZrO}_{2} \geq 65,5 \%\right)$, dan zirkonium silikat di dalam negeri untuk kebutuhan domestik.

- Membentuk lembaga yang mengawasi kandungan radiasi dalam setiap produk berbahan pasir zirkon Indonesia dan memberikan sertifikasi layak jual agar dapat digunakan oleh industri dalam negeri, serta mampu bersaing di pasar internasional.

\section{UCAPAN TERIMA KASIH}

Pada kesempatan ini, ucapan terima kasih disampaikan kepada semua pihak lembaga/ instansi maupun pribadi yang telah memberikan banyak data/informasi, baik langsung maupun tidak langsung sehingga terwujudnya hasil kajian ini dan semoga pula kajian ini bermanfaat bagi bagi para pelaku usaha pasir zirkon, pemerintah, peneliti dan pemerhati zirkon. 


\section{DAFTAR PUSTAKA}

Antara, N. T. dan Sugesty, S., 2011. Industri pulp dan kertas menuju Indonesia green, Prosiding Seminar Nasional Teknologi Mendukung Industri Hijau Kehutanan, Pusat Penelitian Dan Pengembangan Keteknikan Kehutanan Dan Pengolahan Hasil Hutan, Kementerian Kehutanan, Bogor, hal. 63-80.

Dahlan, Y., Pramusanto, Saleh, N., Setyatmoko, E., Sumantri, S. dan Rahmawati, E., 2009. Pembuatan zirkonia dengan metode peleburan pasir zirkon, 77-78, Puslitbang Tekmira, Bandung.

Djamaluddin, Thamrin, M. dan Achmad A., 2012. Potensi dan prospek peningkatan nilai tambah mineral logam di Indonesia (Suatu kajian terhadap upaya konservasi mineral), Prosiding 2012, vol. 6 : Desember 2012, Group Teknik Geologi Hasil Penelitian Fakultas Teknik, Universitas Hasanudin, Makassar, hal. Tg3 1 - Tg3 14.

Distamben Bangka-Belitung, 2013. Daftar IUP dan Produksi Pertambangan di Provinsi BangkaBelirtung, Dinas Pertambangan Provinsi Bangka-Belitung,Tanjung Pandan.

Distamben Kalimantan Tengah, 2013. Daftar IUP dan Produksi Pertambangan di Provinsi Kalimantan Tengah, Dinas Pertambangan Provinsi Provinsi Kalimantan Tengah, Palangkaraya.

Distamben Kalimantan Barat, 2013. Daftar IUP dan Produksi Pertambangan di Provinsi Kalimantan Barat, Dinas Pertambangan Provinsi Provinsi Kalimantan Barat, Pontianak.

Http://www.Alibaba.Com/Showroom/, 2014. Zirkonium-price, Jam 16:55, 30 Maret 2014.

Http://www.Chemicalland21.Com, 2014. General description of zirkonium \& its compounds, Jam 17:01, 30 Maret 2014.

Http://www.Alibaba.Com/Showroom/, Ammonium-zirkonium-carbonate, 2014. 17:30, 30 Maret 2014

Http://www.Abscomaterials.Com/Det/, 2014. Zirkonium-basic-sulphate, Jam 17:41, 30 Maret 2014.

Http://Dir.Indiamart.Com/Impcat/, 2014. Zirkonium-Carbonate.Html, Jam 22:52, 29 Maret 2014.
Http://www.Dixonchew.Com, 2014. Reactive zirkonium chemicals, Jam 21:20, 29 Maret 2014.

Http://www.Sigmaaldrich.Com, 2014. Potassium hexafluorozirkonate, Jam 13:52, 30 Maret 2014.

Http://www.Metalprices.Com/Metal/Zirkonium/, 2014. Zirkonium sponge, Jam 14:02, 30 Maret 2014

Http://Cjmetal.En.Made-In-China.Com, 2014. Zirkonium Basic Carbonate, China Changjiang Nonferrous Metals Co., Limited, , Jam 17:45, 30 Maret 2014.

Http://www.Trulia.Com/Real Estate/, 2014. Zirkonia North Carolina: Market Trends, Jam 18:29, 30 Maret 2014.

Http://www.Lenntech.Com/Periodic/Elements, 2014. Hafnium - Hf, Jam 15:04, 30 Maret 2014.

Kementerian Perdagangan, 2013. Ekspor impor zirkon Indonesia tahun 2007-2013, Pusat Data dan Informasi Kementerian Perdagangan Republik Indonesia, 23 halaman, Jakarta.

Kalteng Mining. Com, 2013. Potensi/sumber daya sirkon Kalimantan Tengah, Jumat, 31 Mei 2013, jam 21:24.

Maharani E., Edwina, S. dan Kusumawaty, Y., 2010. Strategi pengembangan agroindustri nata de coco di Kabupaten Indragiri Hilir, Indonesian Journal of Agricultural Economics (IJAE), vol. 1, no.1, Ekonomi Pertanian (Agrobisnis) Faperta Universitas Riau, Pekanbaru.

Nurbasari A., 2012. Pemberdayaan koperasi dan usaha mikro, kecil, dan menengah di Indonesia, Suatu Tinjauan Rencana Pemasaran, Prosiding Seminar \& Konferensi Nasional Manajemen Bisnis, Universitas Kristen Maranatha, Bandung, hal. 103-112.

Poernomo, H., 2012. Informasi umum zirkonium, Pusat Teknologi Akselerator Dan Proses Bahan, Badan Tenaga Nuklir Nasional, 120 halaman, Yogyakarta.

Raja, M. P, Yusuf A.F., Sayekti B., Mulyana, 2007. Eksplorasi umum endapan zirkon di Kabupaten Katingan, Provinsi Kalimantan Tengah, Kelompok Penelitian Mineral Bidang Sarana Teknik Pusat Sumber Daya Geologi, 7 halaman, Bandung. 
Sajima, Sunardjo, Mulyono, 2012. Pembuatan konsentrat zirkon dari pasir zirkon Kalimantan Barat, Prosiding Seminar Penelitian Dan Pengelolaan Perangkat Nuklir, Pusat Teknologi Akselerator Dan Proses Bahan, Yogyakarta. Halaman berapa dalam prosiding ini?

Suprapto, J.S., 2012. Tinjauan tentang unsur tanah jarang, Buletin Sumber Daya Geologi, vol. 4, no. 1, Pusat Sumber Daya Geologi, 11 halaman, Bandung.

Susanto F.A., Mahendrawati E.R., Ghozali K., 2012. Analisis perbandingan portofolio aplikasi menggunakan teknik balanced scorecard, critical success factors dan SWOT. Studi Kasus Di Unisda (Universitas Islam Darul Ulum) Lamongan, Prosiding Seminar Nasional Manajemen Teknologi XV, Program Studi Mmt-lts, Surabaya, hal.C-8-1 C-8-8.

Suseno, T., Suciyanti, M., dan Suherman, I., 2015. Analisis prospek pemanfaatan zirkon dalam industri keramik, frit, bata tahan api dan pengecoran logam, Jurnal Teknologi Mineral dan Batubara, vol. 11, no. 2, hal. 93-106.

Suseno, T., 2015a. Analisis prospek pasir zirkon Indonesia di pasar dunia, Jurnal Teknologi Mineral dan Batubara, vol. 11, no. 1, hal. 61-77.
Suseno, T., 2015b. Perkiraan biaya pengolahan pasir zirkon ( $\left.\mathrm{ZrSiO}_{4}\right)$, Puslitbang Teknologi Mineral dan Batubara, 21 halaman, Bandung.

Suseno, T., Suherman, I., Prakosa, A., Rochani, S., Permana, D., Saleh, N., Aziz, M.J., Kusnawan, 2013. Prospek pengembangan usaha peningkatan nilai tambah zirkon, Puslitbang Tekmira, Bandung, hal. 20-34.

Sutopo, A. H., dan Arief, A., 2010. Terampil mengolah data kualitatif dengan NVIVO, Penerbit Prenada Media Group, 123 halaman, Jakarta.

www.litbang.esdm.go.id/buku-km/pembuatanzirkonia-dengan-metode-peleburan-pasirzirkon, 2015. Pembuatan zirkonia dengan metode peleburan pasir zirkon, Laporan Kegiatan, Badan Penelitian dan Pengembangan ESDM, Jakarta.

www.mineraldeposits.com.au, 2013. Zircon and titanium mining and processing, Investor presentation, October 2012, Kamis Juli 2013, jam 19:21.

www.Mmta.Co.Uk/, 2014. Hafnium, Avon Metals Ltd., Steven Munnoch, Jam 13:33, 30 Maret 2014. 